\title{
Procesos y Modelos en el Devenir del Turismo en Argentina
}

\begin{abstract}
Juan Carlos Mantero ${ }^{1}$
RESUMEN: La presente contribución es resultado de una interpretación del devenir de la actividad turística en nuestros países y que permite identificar la entidad de tres modelos de desarrollo turístico (la artesanía turística, la industria turística y la red turística) que, de acuerdo a la realidad observada en Argentina y apreciada respecto de otros países, a nuestro criterio, explican el devenir de la actividad en nuestros países y confieren sentido a una prospección del futuro.

De acuerdo a las premisas concebidas al plantear el tema del devenir de la actividad turística resulta necesario afrontar el desafío de un desarrollo integral de nuestras potencialidades y, en tal sentido, se impone la adopción de un modelo de red turística que permita asumir las unidades producto de la artesanía, asimilar el impacto de la industria y generar opciones turísticas en función del objetivo indicado.
\end{abstract}

PALABRAS CLAVES: evolución turística, desarrollo turístico, modelos turísticos, Argentina.

\begin{abstract}
The results from a near future touristic activities interpretation, allows us to identify three major development touristicmodels the handicrafts, the industry and the trade tourism.

In order to evaluate the near future activities in Argentine will be necessary to face the integrated challenge development of tourism opportunities.
\end{abstract}

\footnotetext{
1. Arquitecto, especializado en Developpement y Amenagement du Territoire en Francia y en Gestión Ambiental del Desarrollo Urbano en Argentina. Profesor Titularde Política Turística y Recreativa y de Planificación del Turismo y la Recreación de la Facultad deCiencias Económicas y Sociales de la Universidad Nacional de Mardel Plata. Director del Centro de Investigaciones Turísticas y de la revista Aportes y Transferencias. Asesor de Planificación Turística de la Provincia de Buenos Aires.

E-mail: citurist@mdp.edu.ar
} 
It is necessary to adopt a trade toruism model, which allows to assume the handicriate tourism options.

KEYWORDS: touristic models development, Argentine.

\section{Introducción}

Plantearse una reflexión respecto del devenir de la actividad turística en nuestros países del cono sur es condición necesaria para plantearse una prospección apropiada que permita concebir el escenario que de lugar a la construcción social y económica de una realidad diferente y mejor que permita asumir los recursos disponibles, generar los productos necesarios y defiinir los destinos prioritarios.

Tal premisa no puede plantearse sin mediar un proyecto de desarrollo de la actividad turística que trascienda una mera proyección de crecimiento, apreciable en indicadores, e implique una opción integral que le constituya en satisfactor de necesidades del turista y del residente, cuya intensidad en ciertas áreas turísticas no excluya su extensión a centros de apreciable hospitalidad.

El devenir en Argentina presenta, respecto de otros países, la singularidad de sustentarse en el turismo interno en el período de su expansión y prescindir de tal sustento en el actual período de repliegue, signado por una convocatoria que privilegia el turismo receptivo y sin embargo no genera una afluencia acorde a las expectativas proclamadas.

En tal sentido, la prospección que se formula sugiere la adopción de una política que consecuente con un incremento equitativo y significativo de la calidad de vida de los argentinos permita sustentar a partir del turismointerno la convocatoria a la afluencia de turistas procedentes de otros países.

\section{El Devenir}

El despliegue de la actividad turística en el tiempo y en el espacio hasta alcanzar la difusión actual de expectativas crecientes en Argentina es consecuencia de diversos factores: la disposicion del tiempo, la accesibilidad del espacio, la disposición de excedente y la apetencia del consumo diverso de productos y prestaciones.

A través del tiempo, etapas discernibles en el desarrollo de la economía argentina signan cambiantes circunstancias culturales, sociales y políticas, que condicionan el devenir de las actividades turísticas y recreativas, a partir de fines del siglo XIX y principios del siglo XX, identificando el destino privilegiado de los beneficios producidos al canalizar excedentes de sus beneficiarios en la satisfacción de sus aspiraciones preferentes en tiempo de ocio.
Aquellas etapas permiten identificar la succsión del modelo de economía primaria agroexportadora, agotado hacia 1945, el modelo de economía industrial no integrada de sustitución de importaciones, vigente hasta 1975 y el modelo de apertura económica define la fase actualmente en curso.

Reconocibles en el devenir socio económico, tales etapas tiencn su correlato en las diferentes y sucesivas pautas respecto del rol del Estado (liberal-socialpostsocial), de su relación con la socicdad (garante-interventor-subsidiario), de la mediación de intereses (patrimonialista-neocorporativa-pluralista), en el referente de la acción colectiva (el ciudadano-el trabajador-cl consumidor), en lo atinente al modelo cultural (cl individualismo-el igualitarismo-cl individualismo competitivo)

En tal sentido, el turismo como actividad privilegiadamente beneficiaria del destino de los excedentes económicos y tributaria de los referentes culturales en cada una de las fases, se correlaciona con la accesibilidad diferencial al turismo de los diferentes sectores socioeconomicos nacionales (turismo de elite-turismo de masasturismo de segmentos) y respecto de la variable participación de flujos turísticos externos.

Así, respecto de la actividad turística de fluencia nacional, se observa un período de crecimicnto gradual, simultáneo a la fase agroexportadora, acorde a la limitada redistribución de la renta, un período de cxpansión intensa coincidente con la fase de sustitución de importaciones, al ampliarse la redistribución, un período de equilibrio, beneficiario diferido de dicha fase en tiempos de inflexión, y un período de repliegue y redefinición de la actividad turística, coincidente con la lase de apertura de la economía, sensible a los efectos regresivos en la distribución.

En tales períodos, resulta sintomático observar una tendencia inversa al flujo y reflujo de turistas nacionales en el país, en la efluencia de turistas nacionales fuera del país y de afluencia de turistas extranjeros al país, más allá de magnitudes que pretende acreditar una incierta estimación y/o difusión de estadísticas.

A nuestro criterio, comprender la actividad turística en Argentina implica delinear modelos reconocibles en el devenir y prospectables respecto del avenir de la actividad turística. Cada modelo es expresión de políticas turísticas, implícitas o explícitas, que resultan del propósito de persistencia e insistencia en opciones diferenciadas y en la práctica excluyentes.

Los modelos reconocibles en el devenir remiten a nociones que confrontadas plantean las diferencias: el modelo de la artesanía turística y el modelo de la industria turística, en tanto que en nuestra proposición de supcrar la incertidumbe que signa el presente, se plantea la opción incluyente del modclo de la red turística.

\section{La Artesanía Turística}

La noción de artesanía aplicada a la actividad turistica aspira a caracterizar el modo de generación y desenvolvimiento de equipamientos y servicios turísticos concebidos en respuesta a las inmediatas utilidades funcionales planteadas por el 
turista de trasladarse, alojarse, alimentarse y recrearse, mediante unidades de pequeña y mediana dimensión operativa, conformando el modelo predominante en el desenvolvimiento de la actividad.

El modelo de la artesanía turística, atomístico y espontáneo, asume la satisfacción de la demanda a través de la oferta de operadores dispersos que procuran obtener el máximo beneficio compatible con la prestación mínima a una clientela de exigencias limitadas y prácticas recurrentes, que caracterizara la participación de los sectores medios en la actividad turística en el lapso 1945-1975, y cuya presencia todavía perdura, no obstante el repliegue de los sectores que le dieron origen y el cambio en las modalidades de hacer turismo.

Delineado por las espontáneas y diferentes estrategias de los múltiples operadores turísticos y por las políticas inducidas a través de los agentes públicos el modelo deja librado el resultado de la actividad al arbitrio y el recurso de las unidades turísticas privadas

El modelo de la artesanía turística es la expresión de la puesta en valor de recursos y de servicios a partir de las acciones espontáneas de medianas y pequeñas empresas, no pocas de conformación familiar, que dispersaron sus semillas en áreas de muy disimil aptitud turística en función de la voluntad y la tenacidad, con prescindencia de evaluaciones racionales, prestando los servicios inmediatos requeridos por el turista.

Así, el modelo acompañó la evolución de la actividad, canalizando tanto la inversión de promotores cuanto el ahorro del turista, producto de los beneficios de la economía agroexportadora y, con más amplitud e intensidad, de la economía de la sustitución de importaciones, a partir del estímulo al turismo interno y la disuación del turismo emisivo.

El modelo atomístico de la artesanía turísticaque produce el desenvolvimiento creciente de la actividad remite a ciertos atributos: la diseminación de recursos, la desarticulación de servicios, la espontaneidad de los productos, indiferenciación de funciones, dispesión y desincronización de actividades, el uso ilimitado de los espacios, la maximización del beneficio económico, la dispersión de las decisiones y políticas incongruentes de intereses desarticulados.

La expansión de la actividad turística inscripta en el modelo supuso tiempos de tensa convivencia con el modelo de turismo social compartido por el Estado y las entidades sindicales, actualmente en repliegue, y de difícil competencia con la actividad inmobiliaria en el sector y el desarrollo de una modalidad doméstica en el devenir de la actividad, actualmente en transformación.

De la entidad del modelo da cuenta el diagnóstico del documento Bases para un Plan Federal de Turismo producto de estudios realizados por el área técnica de turismo a nivel nacional a principios de la década el 80 que en su aspiración de superar los problemas identificados propone la adopción de una visión sistémica y la consecución de políticas vertebradas a partir del sector público.

El modelo de la artesanía turística, que en algún momento comparte la conformación del sector con la acción estatal, conoce en tiempos recientes la creciente competencia del modelo de la industria turística, en función del incremento de flujos turísticos internacionales y la radicación de capitales extranjeros producida en la última década.

\section{La Industria Turistica}

La noción de industria aplicada a la actividad turistica aspira a caracterizar el modo de generación y desenvolvimiento de equipamientos y servicios turísticos concebidos a imagen y semejanza de la respuesta a la expansión del negocio turístico de los países centrales emisores en los países periféricos receptores, a través de la canalización de flujos con destino a unidades integradas de prestación de servicios, conformando un modelo en creciente proyección.

El modelo incrementalista de la industria turística que produce la expansión de la actividad en beneficio casi excluyente de sus promotores y operadores, remite aciertos atributos: la uniformización de los productos, especialización de funciones, sincronización mecánica, concentración de actividades y uso intensivo de los espacios, maximización del beneficio financiero, centralización de las decisiones y políticas afines a intereses concentrados, con exclusión de instituciones y empresas involucradas en la actividad.

El modelo, producto de la concepción de sus promotores, privilegia el valor de cambio en la modalidad de promoción y operación, inducida por la cierta estrategia de marketing, susceptible de asimilarse a la noción del turismo de un solo país, inequívoca correlación estereotipada de demanda-oferta en escenografías diferentes.

La apertura de la economía, incentiva el modelo de la industria turística, acentúa la vulnerabilidad de las opciones generadas por las economías regionales en función de las demandas internas, e induce la crisis por irrupción de alternativas turísticas y recreativas inéditas producto de inversiones externas, a partir de la puesta en valor de los recursos - el ambiente natural, cultural y urbano - en función de la puesta en operación de empresas transnacionales.

Cuestiones críticas se suscitan comoconsecuencia de las concentración de la actividad turística en el espacio y en el tiempo, producto de las tendencias a enclavar y a estacionalizar de la actividad a impulso de la industria generando conflictos fricciones turísticas - por la intensidad del fenómeno en unidades espaciales y temporales.

Tales fricciones suelen generar tensiones nuevas, confrontación cultural e impacto tecnológico y económico en el contexto de su implantación, acentuando las inequidades de acceso al tiempo libre y a las oportunidades recreativas inducidas, en ausencia de opciones asociativas de turismo y recreación.

En Argentina, en particular en centros urbanos y metropolitanos destinatarios de la inversión turística, tal como se ha planteado se produce el impacto del modelo de la industria sobre el difuso ámbito de acción del modelo de la artesania, sin mediar asimlación gradual y benéfica de su impacto. A dicho impacto se agrega aquel que producen la industria del shopping y del entretenimiento, concentrada en centros 
metropolitanos, con el dual efecto de atracción de turistas, procedentes de otros centros emisores, y de retención de residentes, potenciales turistas de otros destinos receptores.

De la entidad del modelo da cuenta el documento Tourism Investment and Business Opportunities y el plan de acciones promocionales del área de turismo a nivel nacional a mediados de la década del 90 que en su aspiración excluyente de inducir la afluencia de inversiones y turistas identifica y promueve megaproductos concebidos en función la expectativa externa y prescindencia de la problemática propia como estrategia política del sector público.

El proceso de globalidad en curso se introduce en nuestro país a partir de las reeestructuraciones de unidades independientes que plantean los franquiciados, las cadenas voluntarias y las agrupaciones ad-hoc, y las concentraciones de integración, verticales y horizontales, a través del grupo de empresascomplementarias y el grupo de empresas afines.

El modelo de la industria alcanza así una fase que trasciende la lógica de cada empresa turística y de sus empresarios y permite preveer una lógica industrial y financiera, producto de la convergencia de motivaciones diversas de economía de escala, afluencia de inversiones, necesidad de diversificación, requisito de diferenciación, planteando en las empresas turísticas modalidades de gestión singular y específica.

En tal contexto, al impulso de la apertura, los segmentos en aptitud de consumo turístico de nuestro país, en su momento usufructuarios de destinos nacionales, en el contexto de la transnacionalización se constituyen en la demanda potencial privilegiada de la accion promocional de destinos en otros países.

La conformación de un mercado global y la expansión de los servicios induce una especialización de centros, regiones y países generando un espaciodialécticamente integrado y fragmentado, de asimétricas condiciones y posibilidades. La expansión de la actividad en un contexto de apertura suele implicar apropiación externa del valor del lugar y transferencia externa del valor generado por la actividad.

La insuficiencia e incapacidad de los modelos turísticos identificados - la artesanía turística por ensimismado y la industria turística por enajenado constituye en cuestión la necesidad de concebir una alternativa apropiada para construir y desarrollar una opción de desarrollo turístico relacionado a las expectativas y posibilidades en nuestro medio.

El desarrollo de una alternativa apropiada permitiría atenuar el impacto de una transnacionalización que en la economía del turismo posibilita la concurrencia de mecanismos de transferencia o retención de la renta en los sitios donde se concentran condiciones de control de las decisiones que inciden en la fluencia de personas, tecnologías, informaciones y capitales.

El turismo así concebido plantea una frontera en expansión de aquellos servicios que presta y en la producción de los bienes y de los servicios que insume, y además define las condiciones de accesibilidad de cada lugar en el mercado de consumo, refuerza la estructuración y calificación de los espacios que asume e incluye.
Prospección: la Red Turística

Atento la crisis suscitada por tendencias disociadas, es menester plantearse alternativas que se inscriban en una opción diferente de aquellas que resultan de los modelos identificados.

Tal opción no puede prescindir los recursos que hicieron al desarrollo espontáneo de nuestras posibilidades al servicio de demandas nacionales - ayer crecientes y hoy decrecientes aunque expectantes - ni de aquellos recursos que en otros países hicieran al desarrollo deliberado nuestras posibilidades al servicio de demandas internacionales, aunque no necesariamente en beneficio socio economico.

En tal sentido, cabe rescatar la proposición de un modelo alternativo radicalmente diferente - al modelo de la industria turística, basado en una concepción humanista a partir del ocio, como una totalidad conformada por la vivencia de la realización personal y social y una serie de actitudes y actividades congruentes con una posición reflexiva de la conciencia, que requiere modalidades empresariales, escenarios y actividades cualitativamente distintas.

Tal concepción, que puede observarse en opciones para la práctica de un turismo alternativo a partir de programas y proyectos en curso, de empresarios, grupos y asociaciones en función de un turismo ambiental y cultural, nos resulta compatible e integrable a un modelo de convivialidad turística, susceptible de concebir a partir de la recuperación e integración de aquel modelo de la artesanía turística, rescatando proyectos y emprendimientos del modelo de la industria turística, afirmando una alternativa de desarrollo superador de las alternativas de evolución espontánea y crecimiento unidimensional.

El rescate de la miríada de actividades y servicios que, en función de recursos y escenarios muy diversos, han surgido al impulso de innumerables pequeñas y medianas empresas, susceptibles de actualización y calificación, y la promoción de creativos e innovadores emprendimientos, a escala humana, localizables en áreas y centros priorizables, permitiría conformar un tejido, cuya urdimbre articule agentes receptores y cuya trama relacione agentes emisores, inspirados en propósitos similares, que les integre y confiera perspectivas de desarrollo.

El modelo de la red turística conduciría a un desarrollo en beneficio de turistas y residentes, usuarios y prestatarios, actores y operadores turísticos, privilegiando las condiciones: desmasificación de los productos, diferenciación de funciOnes, sincronización orgánica, desconcentración de actividades,

beneficio socio económico, descentralización de las decisiones e integración productiva y recreativa de turistas y residentes.

De la entidad prospectiva del modelo da cuenta el proceso de transferencia y asunción de la responsabilidad de planificación del nivel nacional al nivel provincial, producida en la década del 80 , y del nivel provincial al nivel municipal, producida en la década del 90, acreditada en la realización de sucesivos seminarios nacionales de muncipios turísticos y la gradual y creciente asociatividad a nivel local de las empresas de servicios turísticos o de servicios involucrados en la actividad, 
acreditada en la creación de entidades sectoriales.

La confrontación con las condiciones inherentes a los modelos de la artesanía turística y de la industria turística permite identificar y acreditar sus potencialidades y posibilidades. Si bien las actuales circunstancias, por imperio de políticas en curso, no parecen propicias al desarrollo de un modelo de convivialidad, la conciencia de su necesidad, en un sector turístico integrado, puede conferirle potencia suficiente para inducir políticas fundacionales y promocionales.

Tal actitud resultaría improbable, si el sector turístico integrado consiente políticas de apertura de la economía en el turismo, que centralicen las decisiones y concentren los beneficios, en función de la exportación de nuestras demandas internas y de la importación de ofertas externas, a través del sentido del flujo de turistas y de capitales.

Los intereses transnacionales, en su articulación de demandas y ofertas, operan con las demandas generadas y las ofertas radicadas en nuestros países estimulando los flujos entre nuestros países, con frecuente prescindencia de las áreas y centros turísticos que vertebrarían nuestra integración y de los sectores y operadores que podrían estructurar el desarrollo turístico.

Las empresas turísticas localizadas frente la impacto de las operaciones de las empresas turísticas globalizadas, por incapacidad del modelo de la artesanía e imperio del modelo de la industria, suponen un desafío para las pequeñas y medianas empresas requiriendo e induciendo estrategias de consolidación en el rubro de hotelería y de expansión en los rubros de agencias, restauración y recreación, planteando un management definidamente empresarial.

Afrontar el problema implica asumir que el objetivo del sector turístico es promover y vender productos integrados o productos singulares segmentados, atendiendo al requerimiento de una necesaria coordinación, lo mas socializada posible, atento el previsible impacto de la empresaintegrada y globalizada, asumiendo la potencialidad de un turismo entendido como assemblage en el contextio del propiciado modelo de la red.

La realización de una reflexión respecto de los modelos y la proposición de un modelo de superación en la construcción del devenir de la actividad en nuestros países, solo podrá resultar del debate suscitado por las realidades en construcción y por los modelos subyacentes que permiten inferir acciones posibles.

En tal sentido, el modelo de la red turística al que remite nuestra proposición, incluso trascendiendo fronteras, asume la potencialidad de un tejido que de sostén a las espectativas y actividades de los turistas, primordialmente de nuestros centros emisores, a través de la malla de oportunidades, espacios y servicios generados por los residentes y los operadores, prioritariamente de nuestras áreas destino de flujos turísticos.

La viabilidad del modelo de la red turística radica en procurar la coordinación e interacción mas socializada posible entre los agentes turísticos privados, en cada uno de nuestros centros, regiones y países en primer instancia y en su relación emisión-recepción respecto de nuestros países limítrofes.

La actividad turística involucra agentes - el operador, el prestador de servicios, el animador, el transportador, el distribuidor oferente, el promotor de emprendimientos - cuyo assemblage suele darse espontáneamente en países de economías desarrolladas e integradas.

En Argentina, país de gestión turística pequeño y mediano empresaria, urdi y tramar el tejido se torna de conformación indispensable e insustituible, en tanto la red turística conforma una opción de puesta en valor y en desarrollo de nuestros recursos y posibilidades en cada una de las escalas en que medie voluntad y decisión.

Frente a las grandes maniobras de reestructuración y concentración en la industria turística y a las acotadas acciones de actualización y modernización de la artesanía turística que singularizan el momento actual, sumado a la distorsión introducida por el desarrollo del inmobiliario turístico, es necesaria la acción concertada del sector público y privado de nuestro país a diferentes niveles de acción y gestión turística.

Afrontar la crisis de la artesanía y asimilar el impacto de la industria requiere estructurar gradualmente la red turística que en cada uno de los niveles coordine e integre sistémicamente la proposición de alternativas turísticas y productos recreativos, requiriendo la definición de políticas que, incluso a escala regional entre los países, implique fluencia recíproca en la emisión y recepción de turistas y que en su proyección convocante vertebre acciones compartidas en los espacios turísticos integrables.

\section{Conclusiones}

La confluencia de concepciones afines respecto del proceso en curso y de prácticas compatibles de acción y gestión en respuesta a necesidades y aspiraciones de los actores involucrados en el devenir turístico, supone la construcción compartida y simultánea de un paradigma que se corresponda con la singular red turística propiciada.

Dentro del modelo de red turística planteada el reconocimiento de los centros urbanos y turísticos que han de conferirle nodalidad a la trama de relaciones planteadas y destino y escala a los flujos turísticos resulta condicion necesaria a la vertebración del territorio en función turística y a la premisa de implicar el devenir de la actividad en el desarrollo local.

La opción de una alternativa de las condiciones planteadas se constituye en condición necesaria para que el desarrollo de la actividad turística sustentada en el turismo interno pueda estimular y vertebrar productos persuasivos y destinos atrayentes de convocatoria de flujos de turismo receptivo, atenuando la incidencia creciente del turismo emisivo en la economía de nuestros países. 


\section{Bibliografia}

ACERENZA, Miguel Angel. 1997. Reflexiones sobre la planificación del turismo en Latinoamérica. APORTES transferencias, año 1, v. 2, Mar del Plata, CIT UNMdP.

ALTES MACHIN, Carmen. 1995. Marketing y turismo. Madrid: Editorial Síntesis S.A.

BALASTRERI RODRIGUEZ, Adyr (Org.). 1997. Turismo e desenvolvimento local. Sao Paulo: Hucitec.

BOULLON, Roberto. 1997. Turismo y ciudad. APORTES y transferencias, año 1, v. 2, Mar del Plata, CIT UNMdP.

GARCIA CANCLINI, Nestor. 1997. Consumidores y ciudadanos. México: Grijalbo.

GARCIA DELGADO, Daniel. 1994. Estado \& sociedad. Bueno Aires: Tesis Grupo Editorial Norma S.A.

GARCIA DELGADO, Daniel. 1997. Nuevos escenarios locales. El cambio del modelo de gestión. In: DGD (Comp.) Hacia un nuevo modelo de gestión local. CBC. Buenos Aires: Universidad de Buenos Aires.

GUEDES FALCAO, José A. 1995. O turismo internacional e os mecanismos de circulacao e transferencia de renda. In: YAzIGI y otros (Org.). Turismo: espaco, paisagem e cultura. Sao Paulo: Hucitec.

GUTIERREZ, Carlos y BORDAS, Eulogio. 1993. La competitividad de los destinos turísticos en mercados lejanos. AIEST, Suiza, St-Gall.

LEBRET, Joseph Louis. 1967. Dinamique concrete du developpement. Economie et Humanisme. Paris: Ouvrieres.

LEFEBVRE, Henri. 1968. Le droit a la ville. Paris: Anthropos.

MANTERO, Juan Carlos. 1997. Turismo: una opción incluyente. Aportes y transferencias, año 1, v. 2, Mar del Plata: CIT UNMdP Brasil.

1998. Tiempo libre y calidad de vida urbana. V CONGRESO MUNDIAL DE TIEMPO LIBRE. São Paulo:

1999. Actividad turísticay desarrollo local. In: AMADASI, Enrique. Política Turística Argentina. Buenos Aires: Editorial Ladevi.

MANTERO, Juan Carlos y equipo del CIT. 1998-2000. Investigación: centros turisticos del litoral atlántico. Informe presentado en CONICET. Inédito.

MAX NEEF, Manfred. 1993. Desarrollo a escala humana. Montevideo: Editorial Nordman-Icaria.

MOLINA, Sergio y otros. 1987. Planificación integral del turismo: un enfoque para Latinoamerica. México: Editorial Trillas.

MUNNE, Frederic. 1980. Psicosociologia del tiempo libre. Un enfoque crítico. México: Trillas.

ORGANIZACIÓN MUNDIAL DEL TURISMO. 1999. Agenda para planificadores locales: turismo sostenible y gestión municipal. (Autores Marchena Gomez, Vera Rebollo, Fernandez Tabales y Santos Pavon) Madrid: OMT. 2000. Guia para administraciones locales: Desarrollo turistico sostenible. (Autor Edward Inskeep - revisor E. Yunis) Madrid: OMT.

RITCHIE, J.R. Brent y GOELNER, Charles. (Eds.). 1994. Travel, tourism and hospitalityresearch. New York: John Wiley \& Sons, Inc.

ROBIROSA, Mario. 1996. Organización y gestión comunitaria. Mar Del Plata: CIAM. Universidad Nacional de Mar del Plata.

SECRETARIA DE TURISMO DE LA NACION. 1993. Argentina. Tourism investment and business opportunities. Buenos Aires.

SUBSECRETARIA NACIONAL DE TURISMO. 1984. Bases para un plan federal de turismo. Buenos Aires: Ministerio de Economía.

VALLS, Josep Francesc. 1992. La imagen de marca de los paises. Barcelona: Mc Graw Hill. ESADE. . 1996. Las claves del mercado turístico. Bilbao: Editorial Deusto.

VERA R., Fernando (Comp.). 1997. Análisis territorial del turismo. Barcelona: Editorial Ariel S.A. 1994. Municipio y turismo. In: ¿España, un país turisticamente avanzado? Instituto de Estudios Turísticos.

VILLASANTE, Tomás. 1998. Metodologia de intervención y gestión local. Módulo de curso. Mar del Plata: CIAM Universidad Nacional de Mar del Plata. 